\title{
Can anthocyanin presence ameliorate the photosynthetic performance of Prunus saplings subjected to polyethylene glycol-simulated water stress?
}

\author{
E. LO PICCOLO*, M. LANDI,**,+, T. GIORDANI", G. LORENZINI ${ }^{* * * *}$, F. MALORGIO*, R. MASSAI*, \\ C. NALI ${ }^{* * *}$, E. PELLEGRINI ${ }^{*, * *}$, G. RALLO ${ }^{*}$, D. REMORINI ${ }^{*}$, P. VERNIERI ${ }^{* * * *}$, and L. GUIDI ${ }^{* * * *}$ \\ Department of Agriculture, Food and Environment, University of Pisa, Via del Borghetto 80, 56124 Pisa, Italy* \\ CIRSEC, Centre for Climate Change Impact, University of Pisa, Via del Borghetto 80, 56124 Pisa, Italy ${ }^{* *}$
}

\begin{abstract}
The aim was the evaluation of the biochemical and physiological responses of green- (GP) and red-leafed (RP) Prunus cerasifera mature leaves to $20 \mathrm{~d}$ of polyethylene glycol (PEG 6000)-induced water stress in order to elucidate a possible ameliorative role exerted by anthocyanins. At $10 \mathrm{~d}$, the anthocyanin content remained unchanged in RP water-stressed leaves. Photosynthetic rate was lower in GP than that of RP ( $83.4 v s .76 .5 \%$, respectively), paralleled by a higher degree of photoinhibition $\left(\mathrm{F}_{\mathrm{v}} / \mathrm{F}_{\mathrm{m}}\right)$ in GP leaves. Leaves of GP accounted for higher content of soluble sugars at $10 \mathrm{~d}$, when RP only showed a slight sucrose increase. At $20 \mathrm{~d}$ of stress, both morphs recovered their $\mathrm{F}_{\mathrm{v}} / \mathrm{F}_{\mathrm{m}}$ values, suggesting the ability of both genotypes to adjust their photosynthetic metabolism under conditions of water stress. In conclusion, besides the sunscreen role served by anthocyanins, the carbon sink by these flavonoids might have further prevented sugar accumulation and the consequent sugar-promoted feedback regulation of photosynthesis in drought-stressed red leaves.
\end{abstract}

Additional key words: chlorophyll a fluorescence; drought; photosystem II; sugar metabolism.

\section{Introduction}

Trees represent a good indicator of urban ecosystem status and provide multiple benefits in urban environments (Millennium Ecosystem Assessment 2005). Trees are well known to provide important ecosystem services, such as air pollutant removal, carbon sequestration, urban heat island mitigation (Tyrväinen et al. 2005), as well as other socioeconomic benefits; for example, they can improve human mental and physical health due to their aesthetic value (Turner-Skoff and Cavender 2019). Environmental factors (temperature, light, water availability, and pollution) and edaphic conditions (texture, structure, and underground obstacles) strongly influence the performances of tree species in urban areas (Núñez-Florez et al. 2019).

Drought is one of the main constraints for trees in Mediterranean cities (Sjöman et al. 2018). Under waterlimiting conditions, different strategies are adopted by leaves to reduce water losses, which include leaf movement, stomata closure, osmotic adjustment, and enhancement of antioxidant systems (Fang and Xiong 2015). Sugar metabolism is also affected in leaves by drought; an increased content of sugars usually occurs during the first stages of water stress (Pinheiro et al. 2001, Pinheiro and Chaves 2011). This transient sugar accumulation perturbs the overall leaf carbon balance and increases the sensitivity of leaves to photoinhibition due to possible feedback regulation of photosynthesis (Krapp and Stitt 1995, Adams et al. 2013).

Prunus cerasifera Ehrh. var. pissardii plants have a high aesthetic value due to the permanent red color of their leaves, which is attributable to the presence of anthocyanins. Foliar anthocyanins, with their sunscreen role, can also contribute to a better tolerance when red-leafed plants are subjected to abiotic constraints (Chalker-Scott 1999, Karageorgou and Manetas 2006, Winefield et al. 2009, Landi et al. 2013, 2015). Under stress conditions, the ability of anthocyanins to intercept a proportion of supernumerary photons striking chloroplast can ameliorate the plant performance, thereby reducing the risk of photoinhibition (Steyn et al. 2002, Manetas et al. 2003, Zhang et al. 2010, Landi et al. 2014).

Beside their sunscreen prerogative, anthocyanin and sugar metabolism are strictly interconnected, and the sugar-

Received 17 December 2019, accepted 17 February 2020.

+Corresponding author; phone: +39 0502216620, e-mail: marco.landi@unipi.it

Abbreviations: $E$ - transpiration rate; $\mathrm{F}_{0}$ - minimal fluorescence yield in the dark-adapted state; $\mathrm{F}_{\mathrm{m}}$ - maximal fluorescence yield in the dark-adapted state; $F_{m}{ }^{\prime}-$ maximal fluorescence yield in the light-adapted state; $F_{v} / F_{m}$ - maximal quantum yield of PSII photochemistry; $g_{\mathrm{s}}$ - stomatal conductance; NPQ - nonphotochemical quenching; NT - nontranslocated sugars; NT/TOT - nontranslocated/total sugars; PEG - polyethylene glycol; $P_{\mathrm{N}}$ - net photosynthetic rate; T - translocated sugars; T/TOT - translocated/total sugars; WUE - water-use efficiency $\left(=P_{\mathrm{N}} / E\right) ; \Phi_{\mathrm{NO}}-$ quantum yield of nonregulated energy loss; $\Phi_{\mathrm{NPQ}}-$ quantum yield of nonphotochemical quenching; $\Phi_{\mathrm{PSII}}-$ effective quantum yield of PSII photochemistry; $\psi_{\mathrm{w}}$ - predawn water potential.

Acknowledgments: This study was performed in the framework of PRA 2017 project 'Photo-oxidative stress in juvenile and senescent red $v s$. green leaves' financed by the University of Pisa. 
promoted enhancement of anthocyanin contents has been demonstrated in planta (Solfanelli et al. 2006, Das et al. 2012). Therefore, it has been postulated that anthocyanins might offer additional photoprotective functions, such as a sugar-buffering role, which contribute in ameliorating plant performance under stress conditions (Landi et al. 2015, Gould et al. 2018). Recently, a dynamic interplay between anthocyanin biosynthesis, photosynthesis, and sugar metabolism was observed in red-leafed Prunus seedlings during the leaf ontogenesis (Lo Piccolo et al. 2018). The authors observed that anthocyanin biosynthesis maintained an efficient carbon-sink strength in young and senescent leaves, avoiding possible negative effects related to excessive leaf sugar accumulation.

In the urban environment, water stress represents a crucial factor for tree survival for different reasons. Climate change promotes more extended and frequent period of drought (Dai 2011, 2013), with a parallel rise in temperatures and heatwaves, thus increasing the urban heat island effect (Grimm et al. 2008). According to these considerations, the selection of urban trees should be focused on stress resistance and climate adaptation, in addition to the aesthetic appeal (Pauleit 2003). To date, only a few studies have reported the effects of environmental stresses in the urban environment on red-leafed tree species (e.g., Napoli et al. 2016) and only a research work focused on the effect of drought in P. cerasifera var. pissardii in Mediterranean area (Kyparissis et al. 2007). The aim of the present work was the comparison of the leaf response of $P$. cerasifera var. pissardii (with red leaves) and $P$. cerasifera clone 29C (with green leaves) to a shortterm polyethylene glycol (PEG 6000)-induced drought. The attempt was to clarify whether the red morph was more tolerant than the green counterpart and to describe a possible role of anthocyanins in water-limiting conditions.

\section{Materials and methods}

Plant material: One-hundred four-year-old $P$. cerasifera saplings (clone 29C, GP; var. pissardii, RP) were purchased from an Italian nursery (Vivai Battistini, Cesena, Italy) and after a homogeneous selection for size and shape, were grafted onto Myrabolan 29C rootstock in November 2016. For detail of cultivation, see Lo Piccolo et al. (2018). Saplings were maintained under greenhouse conditions until March 2018, when they were transferred to open field conditions at the Department of Agriculture, Food and Environment, University of Pisa, Italy $\left(43^{\circ} 42^{\prime} \mathrm{N}\right.$, $\left.10^{\circ} 25^{\prime} \mathrm{E}\right)$. The experiments started the 3 July and three sampling dates were chosen $(0,10,20 \mathrm{~d}$ after the start of the experiment). During the cultivation period, minimum and maximum air temperatures were $21.2 \pm 1.0$ and $30.6 \pm$ $1.1^{\circ} \mathrm{C}$, respectively. Plants were kept well-watered and fertilised before the imposition of PEG 6000 treatment, which was utilised to simulate the drought condition.

Fifty plants were treated with PEG 6000 solution (150 $\left.\mathrm{g} \mathrm{L}^{-1}\right)$ for $20 \mathrm{~d}$; the other fifty were used as controls and were well irrigated with tap water. All control and treated plants were watered every day (with water or PEG 6000 solution, respectively) through an automated system in order to maintain field capacity.

At each sampling date $(0,10$, and $20 \mathrm{~d}$ after the beginning of the simulated water stress), fully expanded leaves were used for physiological analyses. Leaves homogeneous to those used for physiological analysis were collected and immediately frozen in liquid nitrogen and stored at $-80^{\circ} \mathrm{C}$ until biochemical analysis. All utilised chemicals were purchased from Sigma-Aldrich, Milan, Italy.

Water potential: The predawn water potential $\left(\psi_{\mathrm{w}}\right)$ was determined in a fully expanded leaf per plant $(n=4)$ by a Scholander pressure chamber (model 600, PMS Instrument, Albany, OR, USA).

Leaf gas-exchange and chlorophyll $(\mathrm{Chl}) \boldsymbol{a}$ fluorescence analysis: Gas-exchange parameters were determined in fully expanded leaves $(n=5)$ from $10: 00$ to $14: 00 \mathrm{~h}$ at ambient light and $\mathrm{CO}_{2}$ concentration [on average $1,800 \mu \mathrm{mol}$ (photon) $\mathrm{m}^{-2} \mathrm{~s}^{-1}$ and $\left.390 \mu \mathrm{mol}\left(\mathrm{CO}_{2}\right) \mathrm{mol}^{-1}\right]$. Net assimilation of photosynthesis $\left(P_{\mathrm{N}}\right)$ and stomatal conductance $\left(g_{\mathrm{s}}\right)$ were measured. Instantaneous water-user efficiency (WUE) was calculated according to Medrano et al. (2015) as net assimilation of photosynthesis/ transpiration $\left(P_{\mathrm{N}} / E\right)$ ratio. For the analyses, a portable infrared gas analyser ( $\mathrm{Li}$-Cor 6400, Li-Cor Inc., Lincoln, NE, USA) was used.

Chl fluorescence parameters were measured in fully expanded leaves $(n=5)$ using a PAM-2000 fluorometer (Walz, Effeltrich, Germany). Dark-adapted leaves (30 min) were initially exposed to a weak, modulated measuring beam $\left[<0.2 \mu \mathrm{mol}\right.$ (photon) $\mathrm{m}^{-2} \mathrm{~s}^{-1}$, followed by the exposure to a flash of saturated white light [about 15,000 $\mu \mathrm{mol}$ (photon) $\mathrm{m}^{-2} \mathrm{~s}^{-1}$ and a duration of $800 \mathrm{~ms}$. In this way, the determination of minimal and maximal $\mathrm{Chl}$ fluorescence $\left(\mathrm{F}_{0}\right.$ and $\mathrm{F}_{\mathrm{m}}$, respectively) was determined, and potential quantum yield of PSII photochemistry $\left(\mathrm{F}_{\mathrm{v}} / \mathrm{F}_{\mathrm{m}}\right)$ was calculated. When actinic light is given [500 $\mu$ mol(photon) $\mathrm{m}^{-2} \mathrm{~s}^{-1}$, the photosynthetic light reactions starts and a steady-state fluorescence yield $\left(\mathrm{F}_{\mathrm{s}}\right)$ is reached. The effective photochemical yield of PSII $\left(\Phi_{\text {PSII }}\right)$ was calculated as $\left(\mathrm{F}_{\mathrm{m}}{ }^{\prime}-\mathrm{F}_{\mathrm{s}}\right) / \mathrm{F}_{\mathrm{m}}{ }^{\prime}$, where $\mathrm{F}_{\mathrm{m}}{ }^{\prime}$ is the maximum level of fluorescence yield in the light induced by a saturation pulse over imposed to the actinic light (Genty et al. 1989). The nonphotochemical quenching (NPQ) was calculated according to the equation NPQ = $\mathrm{F}_{\mathrm{m}} / \mathrm{F}_{\mathrm{m}}{ }^{\prime}-1$ of Bilger and Björkman (1990). The quantum yield of nonregulated energy loss and quantum yield of nonphotochemical quenching ( $\Phi_{\mathrm{NO}}$ and $\Phi_{\mathrm{NPQ}}$, respectively) were calculated as $F_{s} / F_{m}{ }^{\prime}$ and $\left(F_{m}{ }^{\prime}-F_{s}\right) /\left(F_{s}-F_{m}\right)$, respectively (Klughammer and Schreiber 2008).

Anthocyanin content: Anthocyanins were extracted as described in Landi et al. (2014) in acidified methanol (1.5\% $\mathrm{HCl}, \mathrm{v} / \mathrm{v})$ overnight at room temperature $(n=3)$, and the absorbance at $535 \mathrm{~nm}$ was determined using an Ultrospec 2100 Pro UV-VIS spectrophotometer (GE Healthcare Ltd., Chicago, IL). Absorbance values were converted to cyanidin-3-O-glucoside equivalents (molar extinction coefficient of $34,300 \mathrm{M} \mathrm{cm}^{-1}$ and molecular mass of $484.3 \mathrm{~g} \mathrm{~mol}^{-1}$ ) and expressed as $\mathrm{mg} \mathrm{g}^{-1}(\mathrm{DM})$. 
Soluble sugar, sorbitol, and starch content: Sugar and polyol quantifications $(n=3)$ were conducted according to Yusof et al. (2016) and Sotelo et al. (2014) with some modifications, as reported in Lo Piccolo et al. (2018). Glucose and fructose content represent the nontranslocated sugars (NT), sucrose and sorbitol the translocated sugars (T), the sum of NT and T sugars represents the total sugar (TOT). Then, the ratios between T/NT, T/TOT, and NT/TOT were calculated.

Statistical analysis: Data were analysed by two-way analysis of variance (ANOVA) using PEG treatment and sampling date as the variability factors, followed by Fisher's least significant difference (LSD) post-hoc test $(p=0.05)$. For Chl fluorescence parameters, a one-way $A N O V A$ test was applied, using the sampling date as variability factor. Before $A N O V A$, the assumption of homogeneity of variances was tested using Bartlett's test. All statistical analyses were conducted using GraphPad (GraphPad, La Jolla, CA, USA).

\section{Results and discussion}

Leaf water potential: Values of $\psi_{\mathrm{w}}$ remained constant in well-watered saplings until the end of the experiment (about $-0.5 \mathrm{MPa}$ ), whereas a strong reduction was observed in leaves of water-stressed saplings (about $-1.3 \mathrm{MPa}$; Fig. 1). The reduction was recorded after $10 \mathrm{~d}$ of water stress, and $\psi_{\mathrm{w}}$ values remained unchanged after further $10 \mathrm{~d}$ of stress. The decrease of water potential in Prunus species subjected to water stress has been already reported (Escobar-Gutiérrez et al. 1998, Kyparissis et al. 2007, Mellisho et al. 2011, Jiménez et al. 2013) although in this study the decrease of water potential $\psi_{\mathrm{w}}$ occurred earlier than that in previous research, likely due to the severity of the treatment imposed in our experiments.

Leaf gas exchange, $\mathrm{Chl}$ fluorescence, and anthocyanin content: Ten days after the PEG treatment, $P_{\mathrm{N}}$ declined severely in both GP and RP leaves, but with a higher amplitude in GP than RP leaves (83.4 and $76.5 \%$, respectively). A drastic constraint of $g_{\mathrm{s}}$ values was also observed in both the morphs (Fig. 2). The parallel decline of these two parameters suggests a strong influence of stomatal limitation on $\mathrm{CO}_{2}$ assimilation rate, and it is supportive for previous finding highlighting that stomatal closure represents one of the first response to water limitation (Flexas and Diaz-Espejo 2015). The pattern of $P_{\mathrm{N}}$ and $g_{\mathrm{s}}$ was also maintained in RP morphs at the end of the experiment, in which $P_{\mathrm{N}}$ and $g_{\mathrm{s}}$ values remained similar to those detected at $10 \mathrm{~d}$ (Fig. $2 B, D$ ). Conversely, a slight increase in $P_{\mathrm{N}}$, associated with no significant changes in $g_{\mathrm{s}}$, was detected in GP morphs at $20 \mathrm{~d}$ as compared to the values measured at $10 \mathrm{~d}$ (Fig. $2 A, C$ ). The different behaviour in $P_{\mathrm{N}}$ and $g_{\mathrm{s}}$ detected in GP and RP morphs at $20 \mathrm{~d}$ (compared to values obtained at $10 \mathrm{~d}$ ) highlighted that biochemical limitations were also responsible for photosynthesis impairment.

In water-stress conditions, plants need to optimize carbon and water utilization in relation to stomatal aperture (Manzoni et al. 2011). An increase in WUE value was only detected in RP leaves at the end of the treatments. This parameter has been interpreted as a measure of carbon gain per unit of water loss (Singh and Reddy 2011). The improvement of WUE could play a vital role for plants experiencing water withholding in crops, and therefore also in the urban environment (McCarthy et al. 2011, Singh and Reddy 2011) (Fig. 2E,F).

Chl fluorescence parameters highlight that both the Prunus morphs resulted photoinhibited (i.e., a reduction of $\left.\mathrm{F}_{\mathrm{v}} / \mathrm{F}_{\mathrm{m}}\right) 10 \mathrm{~d}$ after the start of water stress, with lower values in GP (0.67) than that of RP morphs (0.73). In control plants of both morphs, no differences in Chl fluorescence parameters were reported during the experimental period (data not shown). Both stressed GP and RP leaves recovered completely the values of $\mathrm{F}_{\mathrm{v}} / \mathrm{F}_{\mathrm{m}}$ at the end of the experiment $(0.74$ and 0.77 , respectively; Table 1$)$. Similarly, $\Phi_{\text {PSII }}$ decreased after $10 \mathrm{~d}$ more strongly in GP than that in RP (45 and 28\% in GP and RP, respectively) and did not further decrease after $20 \mathrm{~d}$ of the treatment in GP whilst in RP leaves values of $\Phi_{\text {PSII }}$ underwent a further decrement (40\%; Table 1).

Drought-induced photoinhibition is a common response among plant species, including Prunus spp. (Kyparissis et al. 2007, Pérez-Jiménez et al. 2017). The decline of photosynthetic yield under water stress might be partially related to a decreased photochemical PSII activity (Govindjee 2004, Foyer 2018), which generates a surplus of excitation energy in thylakoid membranes not efficiently tunnelled to nonphotochemical dissipative mechanisms

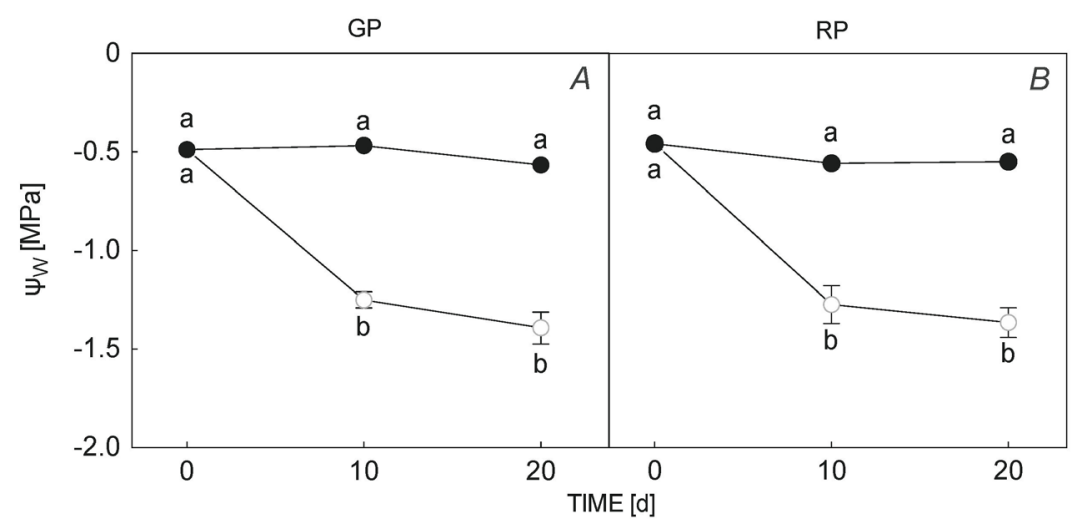

Fig. 1. Predawn water potential $\left(\Psi_{w}\right)$ of leaves of two morphs of Prunus cerasifera saplings with green (GP) or red (RP) leaves subjected to PEG 6000-induced water stress (open circle) or tap-water (control; closed circle). Each point is the mean of four replicates ( \pm standard deviation). Data are subjected to two-way ANOVA with PEG treatment and sampling date as sources of variation. Means flanked by the same letter are not statistically different for $p=0.05$ after Fisher's least significant difference post-hoc test. 


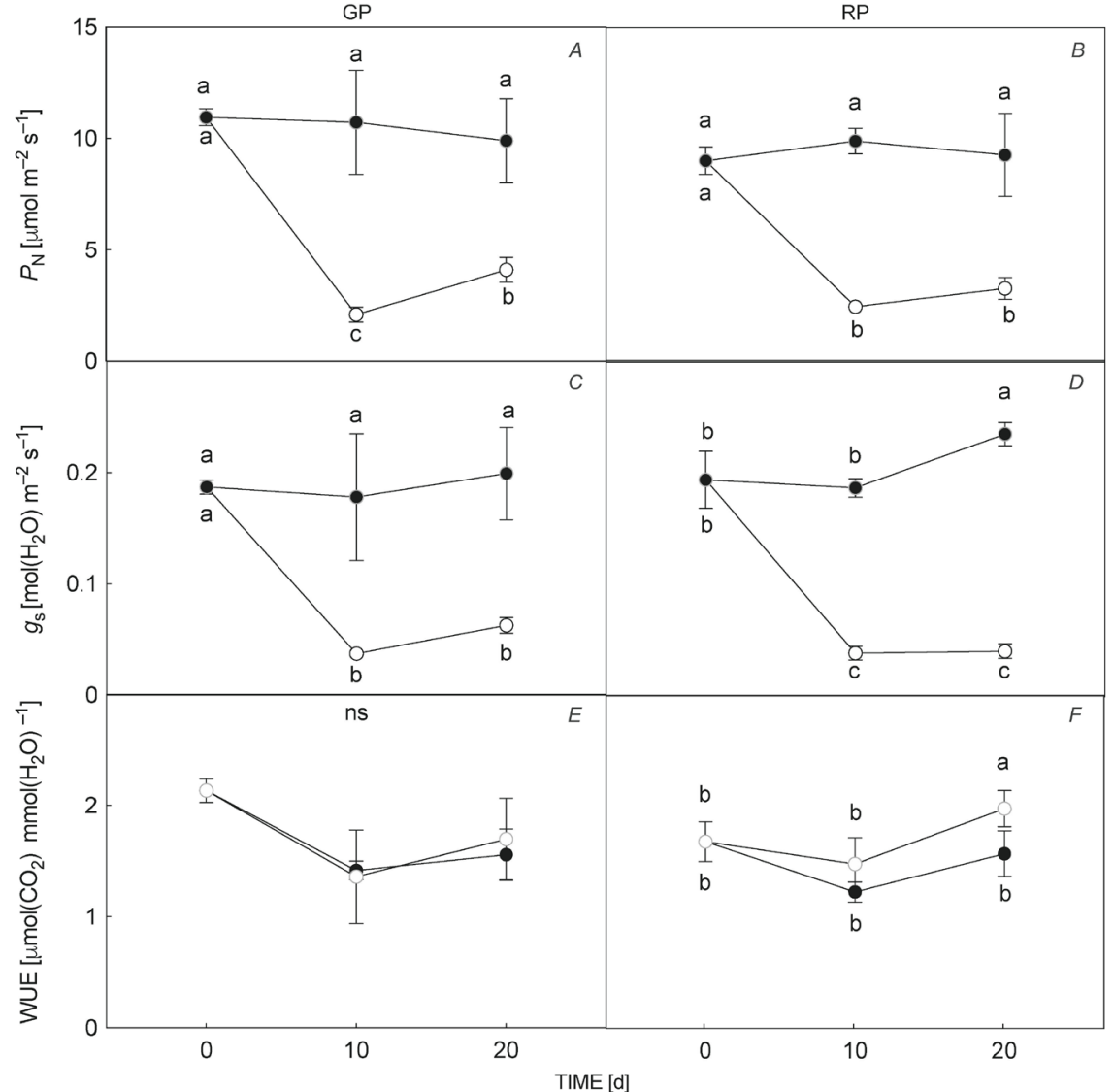

Fig. 2. Gas-exchange parameters of leaves of two morphs of Prunus cerasifera saplings with green (GP) or red (RP) leaves subjected to PEG 6000-induced water stress (open circle) or tap-water (control; closed circle). Each point is the mean of five replicates ( \pm standard deviation). Data are subjected to two-way ANOVA with PEG treatment and sampling date as sources of variation. Means flanked by the same letter are not statistically different for $p=0.05$ after Fisher's least significant difference post-hoc test. The absence of letters indicates nonsignificant interactions between the two factors. $g_{\mathrm{s}}-$ stomatal conductance; $P_{\mathrm{N}}-$ net photosynthetic rate; WUE - water-use efficiency $\left(=P_{\mathrm{N}} / E\right)$.

Table 1. Potential quantum yield of PSII photochemistry $\left(\mathrm{F}_{\mathrm{v}} / \mathrm{F}_{\mathrm{m}}\right)$, effective quantum yield of PSII photochemistry $\left(\Phi_{\mathrm{PSII}}\right)$, quantum yield of nonregulated energy loss $\left(\Phi_{\mathrm{NO}}\right)$, quantum yield of nonphotochemical quenching $\left(\Phi_{\mathrm{NPQ}}\right)$, and nonphotochemical quenching (NPQ) in leaves of two morphs of Prunus cerasifera saplings with green (GP) or red (RP) leaves subjected to PEG 6000-induced water stress. Data of $0 \mathrm{~d}$ represent the start of the experiment. Each point is the mean of five replicates ( \pm standard deviation). Data are subjected to one-way ANOVA with sampling date as sources of variation. Means flanked by the same letter are not statistically different for $p=0.05$ after Fisher's least significant difference post-hoc test.

\begin{tabular}{lllllll}
\hline \multicolumn{2}{c}{ GP } & \multicolumn{5}{l}{ RP } \\
& $0 \mathrm{~d}$ & $10 \mathrm{~d}$ & $20 \mathrm{~d}$ & $0 \mathrm{~d}$ & $10 \mathrm{~d}$ & $20 \mathrm{~d}$ \\
\hline $\mathrm{F}_{\mathrm{v}} / \mathrm{F}_{\mathrm{m}}$ & $0.77 \pm 0.03^{\mathrm{a}}$ & $0.67 \pm 0.05^{\mathrm{b}}$ & $0.74 \pm 0.01^{\mathrm{a}}$ & $0.78 \pm 0.01^{\mathrm{a}}$ & $0.73 \pm 0.02^{\mathrm{b}}$ & $0.77 \pm 0.09^{\mathrm{a}}$ \\
$\Phi_{\mathrm{PSII}}$ & $0.40 \pm 0.04^{\mathrm{a}}$ & $0.22 \pm 0.03^{\mathrm{b}}$ & $0.24 \pm 0.04^{\mathrm{b}}$ & $0.43 \pm 0.04^{\mathrm{a}}$ & $0.31 \pm 0.02^{\mathrm{b}}$ & $0.26 \pm 0.01^{\mathrm{c}}$ \\
$\Phi_{\mathrm{NO}}$ & $0.21 \pm 0.01$ & $0.23 \pm 0.02$ & $0.23 \pm 0.02$ & $0.23 \pm 0.01$ & $0.24 \pm 0.01$ & $0.22 \pm 0.01$ \\
$\Phi_{\mathrm{NPQ}}$ & $0.38 \pm 0.03^{\mathrm{b}}$ & $0.54 \pm 0.03^{\mathrm{a}}$ & $0.52 \pm 0.03^{\mathrm{a}}$ & $0.33 \pm 0.05^{\mathrm{c}}$ & $0.44 \pm 0.01^{\mathrm{b}}$ & $0.51 \pm 0.02^{\mathrm{a}}$ \\
$\mathrm{NPQ}$ & $1.77 \pm 0.08^{\mathrm{b}}$ & $2.29 \pm 0.31^{\mathrm{a}}$ & $2.22 \pm 0.12^{\mathrm{a}}$ & $1.44 \pm 0.24^{\mathrm{c}}$ & $1.87 \pm 0.06^{\mathrm{b}}$ & $2.23 \pm 0.20^{\mathrm{a}}$ \\
\hline
\end{tabular}

(Ruban 2016). Results of the present experiments showed no changes in $\Phi_{\mathrm{NO}}$ during the water stress in both GP and $\mathrm{RP}$, whereas the increment of $\Phi_{\mathrm{NPQ}}$ values highlight that both morphs were able to dissipate the excessive excitation energy through regulated processes (Hendrickson et al. 2004). Indeed, in both morphs, NPQ and $\Phi_{\mathrm{NPQ}}$ increased significantly, but in RP the increase of both parameters paralleled the water stress duration, whereas in GP both increased after $10 \mathrm{~d}$ and remained unchanged at $20 \mathrm{~d}$ (Table 1). However, both morphs recovered completely from photoinhibition at the end of the experiment, which is supportive for the ability of plants, after a first phase of stress and metabolic perturbation, to adjust their metabolism in condition of reduced water availability. Similar results were also demonstrated in both green- and red-leafed Prunus plants during a typical Mediterranean summer (Kyparissis et al. 2007).

The anthocyanin content decreased in control RP leaves $10 \mathrm{~d}$ after the beginning of the experiment, whereas it remained constant in stressed RP leaves. The anthocyanin content was below the instrument detectability in GP leaves. Of note, at $20 \mathrm{~d}$, anthocyanin content drastically decreased in stressed RP whereas it remained unchanged in controls (compared to 10 d; Fig. 3). 
Anthocyanins are usually believed to ensure a photoprotective function in leaves (Hughes et al. 2005, Gould et al. 2018, Moustaka et al. 2018). These pigments, absorbing principally the yellow-green wavebands and a proportion of blue and red light, reduce the photons that would otherwise strike the chloroplast, thereby alleviating excessive excitation pressure to PSII (Harborne 1958, Tattini et al. 2017). This sunscreen prerogative might explain the $\mathrm{F}_{\mathrm{v}} / \mathrm{F}_{\mathrm{m}}$ decrease at a lower extent in RP compared to GP stressed morphs observed at $10 \mathrm{~d}$, and can also explain the constitutive lower level of NPQ in RP control leaves respect to GP, a common feature of red-leafed species (Manetas et al. 2002, Hatier et al. 2013, Hughes et al. 2014, Landi et al. 2014). Leaves belonging to both stressed morphs increased the level of NPQ to dissipate the excessive radiation (10 d) showing higher NPQ values in GP than in RP leaves (2.29 and 1.87, respectively), when the anthocyanin content remained unchanged under water stress. Higher values of $\Phi_{\mathrm{NPQ}}$ detected in stressed GP than $\mathrm{RP}$ at $10 \mathrm{~d}(+42$ and $+33 \%$, respectively in comparison to their relative controls), demonstrated that GP morphs necessitated to dissipate more excitation energy than the anthocyanin-equipped RP morph, in which the mesophyll cells are partially shaded by the anthocyanin layer, thereby reducing the burden of light to chloroplast. Supportively for this sunscreen (photoprotective) role, leaves of RP morphs necessitated to further increase NPQ and $\Phi_{\mathrm{NPQ}}$ at $20 \mathrm{~d}$ (19 and $16 \%$, respectively) in respect to values detected at $10 \mathrm{~d}$, when the anthocyanin content was strongly reduced. This also explains the further decrease in $\Phi_{\text {PSII }}$ values at $20 \mathrm{~d}$ in RP and then the lack of a partial $P_{\mathrm{N}}$ recovery at $20 \mathrm{~d}$ as observed in GP leaves.

The gas exchange, Chl fluorescence, and anthocyanin analyses are supportive for a photoprotective role of anthocyanins and also highlighted a strict interplay between these colourful flavonoids and carotenoids in leaf photoprotection (Hughes et al. 2007, 2012; Lo Piccolo et al. 2018).

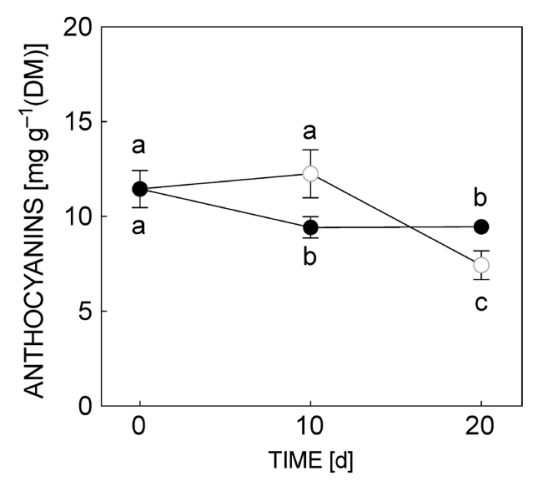

Fig. 3. Anthocyanin content in leaves of Prunus cerasifera var. pissardii saplings leaves subjected to PEG 6000-induced water stress (open circle) or tap-water (control; closed circle). Each point is the mean of three replicates ( \pm standard deviation). Data are subjected to two-way ANOVA with PEG treatment and sampling date as sources of variation. Means flanked by the same letter are not statistically different for $p=0.05$ after Fisher's least significant difference post-hoc test.
Sugar analysis: After $10 \mathrm{~d}$ of water stress, a sharp increase in soluble sugars (glucose, fructose, and sucrose) was observed in leaves of GP (Fig. 4A,C,E), whilst only a slight increase in sucrose was observed in RP morphs (Fig. 4F). However, after further $10 \mathrm{~d}$ of stress, the differences in sucrose content between control and stressed leaves of GP were less pronounced, and fructose content was similar in control and stressed leaves (Fig. $4 A-F$ ). At the end of the experiment ( $20 \mathrm{~d})$, the sucrose content in RP stressed leaves was similar to control plants (Fig. $4 F$ ). In both morphs, a strong increase in sorbitol was observed and its content in GP at $20 \mathrm{~d}$ of treatment was higher than the value recorded at $10 \mathrm{~d}$, whereas in RP leaves at $20 \mathrm{~d}$ (Fig. 4G,H) it was unchanged when compared to values found at $10 \mathrm{~d}$. Sorbitol has been reported to be the main translocating sugar in Rosaceae family (Bieleski and Redgwell 1980) and the increase in sorbitol content is a common response in Prunus plants under drought (Lo Bianco et al. 2000, Rieger et al. 2003). It has been reported that sorbitol plays a key role in leaf osmotic adjustment during drought stress in cherry (Ranney et al. 1991) and apple (Wang and Stutte 1992). Drought-induced perturbation of sugar metabolism was also evident in leaves of both the morphs by the analyses of starch patterns. Starch content decreased in both 10- and 20-d stressed RP and GP leaves when compared with their relative controls, but a stronger decline of starch amount was detected in GP than that in RP leaves after $20 \mathrm{~d}$ of treatment (Fig. $4 I, J$ ).

Besides the classic assumption that anthocyanins serve a sunscreen function in leaves, anthocyanin synthesis further represents an 'expensive' carbon sink (Gould 2004), which, under stress, might contribute to reduce sugar accumulation when plants experience an imbalance between light burden to chloroplast and the rate of carbonassimilating pathway (Steyn et al. 2002, Landi et al. 2015, Gould et al. 2018, Lo Piccolo et al. 2018). Sugar-promoted anthocyanin accumulation was previously demonstrated by Solfanelli et al. (2006), therefore, it has been hypothesized that their biosynthesis limits the accumulation of foliar sugars under stress (Landi et al. 2015). In this way, anthocyanin synthesis might represent a further mechanism by which these pigments prevent photoinhibition, caused by sugar-promoted feedback regulation of photosynthesis (Adams et al. 2013, Eveland and Jackson 2012). The lower reduction in carbon assimilation detected in RP compared to GP, followed by a lower soluble sugar (sucrose, glucose, and fructose) increase observed at $10 \mathrm{~d}$ of water stress is supportive for this hypothesis (Figs. 2-4). In addition, the strong anthocyanin content reduction found in RP stressed leaves at $20 \mathrm{~d}$ of water stress (Fig. 3) is likely attributable to a conservative strategy of RP stressed leaves, in which the production of $\mathrm{T}$ is prevalent, as shown by values of T/NT (Table 2). On the contrary, the lack of the alternative carbon sink of anthocyanins in GP leaves was likely the reason of a further increase of sorbitol, as an attempt to contrast the accumulation of glucose and fructose, which are well-known feedback inhibitors of photosynthesis.

The lower content of sugars in RP vs. GP leaves in the first stages of the stress $(10 \mathrm{~d})$ can be related to two main factors: the biosynthesis of anthocyanins and the higher 


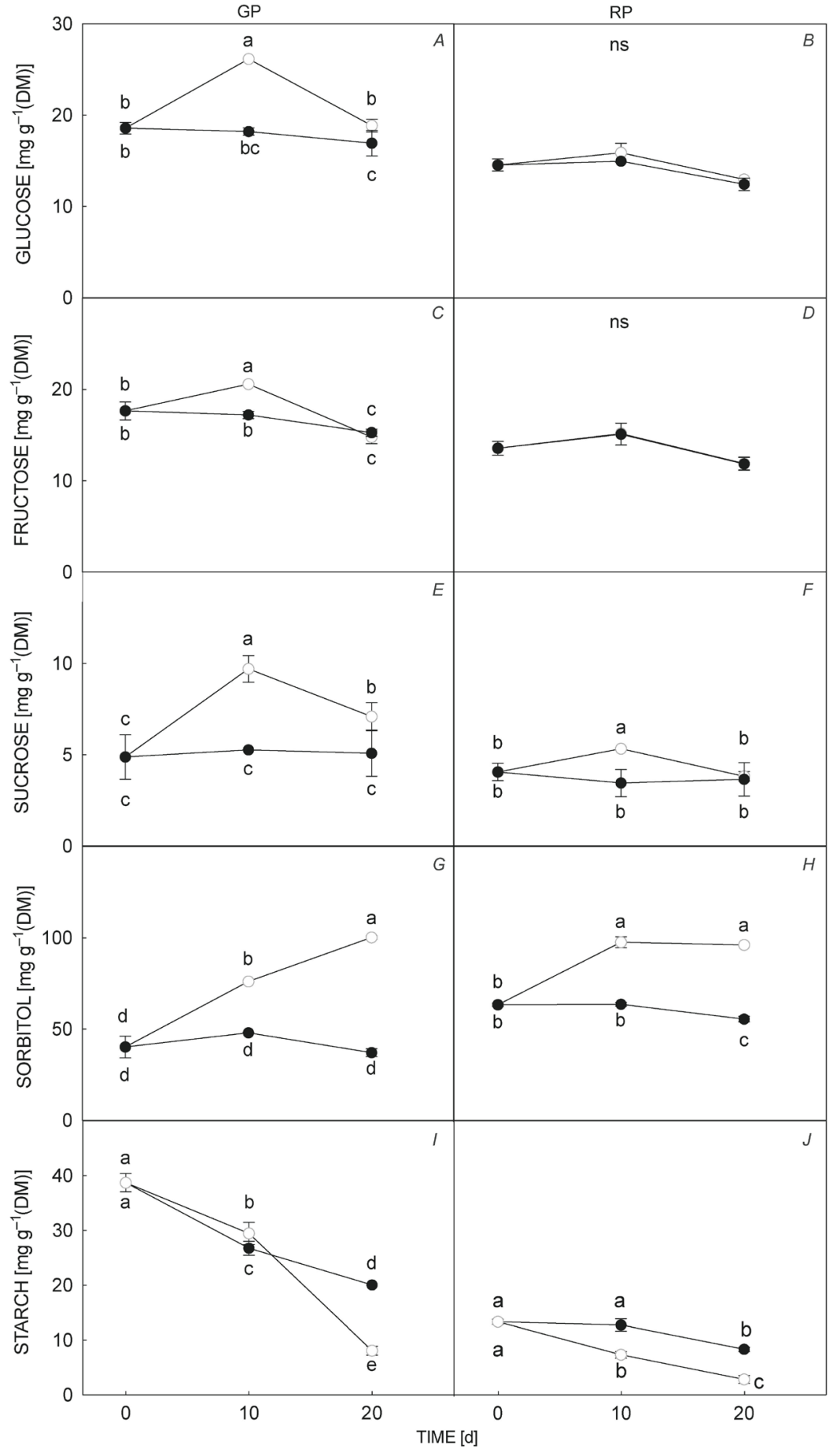

Fig. 4. Sugars content in leaves of two morphs of Prunus cerasifera saplings with green (GP) or red (RP) leaves subjected to PEG 6000-induced water stress (open circle) or tapwater (control; closed circle). Each point is the mean of three replicates ( \pm standard deviation). Data are subjected to two-way ANOVA with PEG treatment and sampling date as sources of variation. Means flanked by the same letter are not statistically different for $p=0.05$ after Fisher's least significant difference post-hoc test. The absence of letters indicates no significant interactions between the two factors. constitutive ability of RP than GP leaves to promote the biosynthesis of T instead of NT sugars, as revealed by the T/NT ratio (1.97 in GP vs. 3.38 in RP leaves; $p<0.01$ ) and T/TOT (0.62 in GP vs. 0.72 in RP leaves; $p<0.05)$ (Table 2). This induced a twofold beneficial effect in RP saplings; firstly, it contributed in limiting sugar-induced photoinhibition, and secondly, this could also favor the supply of sugar to younger tissues, which were not completely developed in their photosynthetic apparatus.
Conclusion: Results of the present experiment suggest that anthocyanins serve a photoprotective function in Prunus leaves when plants are subjected to water stress. The photoprotection exerted by these pigments consists of both their sunscreen and sugar-buffering capacity. In the first case, their ability to absorb a proportion of sunlight reduces the burden of energy to the chloroplast. At the same time, the anthocyanin pathway represents a consistent carbon sink which reduces the probability of feedback regulation of photosynthesis. RP saplings also 
Table 2. Translocated on nontranslocated sugar ratio (T/NT), nontranslocated on total sugar ratio (NT/TOT), and translocated on total sugar ratio (T/TOT), in leaves of two morphs of Prunus cerasifera with green (GP) or red (RP) leaves subjected to PEG 6000-induced water stress (treated) or tap-water (control). Each point is the mean of three replicates ( \pm standard deviation). Data are subjected to two-way ANOVA with PEG treatment and sampling date as sources of variation. Means flanked by the same letter are not statistically different for $p=0.05$ after Fisher's least significant difference post-hoc test. The absence of letters indicates no significant interaction between sources of variation.

\begin{tabular}{|c|c|c|c|c|c|c|c|}
\hline & & $\begin{array}{l}\text { GP } \\
0 \mathrm{~d}\end{array}$ & $10 \mathrm{~d}$ & $20 \mathrm{~d}$ & $\begin{array}{l}\mathrm{RP} \\
0\end{array}$ & $10 \mathrm{~d}$ & $20 \mathrm{~d}$ \\
\hline $\mathrm{T} / \mathrm{NT}$ & $\begin{array}{l}\text { Control } \\
\text { Treated }\end{array}$ & $\begin{array}{l}1.24 \pm 0.08^{\mathrm{d}} \\
1.24 \pm 0.08^{\mathrm{d}}\end{array}$ & $\begin{array}{l}1.50 \pm 0.21^{\mathrm{c}} \\
1.97 \pm 0.10^{\mathrm{b}}\end{array}$ & $\begin{array}{l}1.31 \pm 0.20^{\mathrm{c}} \\
2.69 \pm 0.04^{\mathrm{a}}\end{array}$ & $\begin{array}{l}2.39 \pm 0.10^{c} \\
2.39 \pm 0.10^{c}\end{array}$ & $\begin{array}{l}2.23 \pm 0.04^{\mathrm{c}} \\
3.38 \pm 0.02^{\mathrm{b}}\end{array}$ & $\begin{array}{l}2.43 \pm 0.26^{\mathrm{b}} \\
3.68 \pm 0.22^{\mathrm{a}}\end{array}$ \\
\hline NT/TOT & $\begin{array}{l}\text { Control } \\
\text { Treated }\end{array}$ & $\begin{array}{l}0.44 \pm 0.03^{\mathrm{a}} \\
0.44 \pm 0.03^{\mathrm{a}}\end{array}$ & $\begin{array}{l}0.40 \pm 0.01^{\mathrm{a}} \\
0.38 \pm 0.05^{\mathrm{ab}}\end{array}$ & $\begin{array}{l}0.43 \pm 0.03^{\mathrm{a}} \\
0.34 \pm 0.02^{\mathrm{b}}\end{array}$ & $\begin{array}{l}0.29 \pm 0.04 \\
0.29 \pm 0.04\end{array}$ & $\begin{array}{l}0.31 \pm 0.03 \\
0.28 \pm 0.01\end{array}$ & $\begin{array}{l}0.29 \pm 0.02 \\
0.25 \pm 0.05\end{array}$ \\
\hline T/TOT & $\begin{array}{l}\text { Control } \\
\text { Treated }\end{array}$ & $\begin{array}{l}0.55 \pm 0.03^{b} \\
0.55 \pm 0.03^{b}\end{array}$ & $\begin{array}{l}0.60 \pm 0.03^{\mathrm{b}} \\
0.62 \pm 0.04^{\mathrm{ab}}\end{array}$ & $\begin{array}{l}0.57 \pm 0.03^{\mathrm{b}} \\
0.66 \pm 0.04^{\mathrm{a}}\end{array}$ & $\begin{array}{l}0.70 \pm 0.04 \\
0.70 \pm 0.04\end{array}$ & $\begin{array}{l}0.69 \pm 0.06 \\
0.72 \pm 0.03\end{array}$ & $\begin{array}{l}0.71 \pm 0.03 \\
0.74 \pm 0.06\end{array}$ \\
\hline
\end{tabular}

demonstrated a higher constitutive ability to allocate assimilated carbon to T than NT sugars. In RP leaves, both these features can contribute in limiting sugar-promoted feedback regulation of photosynthesis, which represents another factor responsible for photoinhibition under water stress. This study also highlights the importance to investigate the role of anthocyanins as sugar buffer and the consequences of their presence for leaf photosynthesis in plants under stress deeply.

As an applicative result, we offer the evidence that presence of anthocyanins makes the difference in terms of drought responses between red $v s$. green leaves, at least during a first phase of stress. In a constrained environment such as Mediterranean cities, these features have to be considered for the selection of tree species in the urban environment.

\section{References}

Adams III. W.W., Muller O., Cohu C.M., Demmig-Adams B.: May photoinhibition be a consequence, rather than a cause, of limited plant productivity? - Photosynth. Res. 117: 31-44, 2013.

Bieleski R., Redgwell R.: Sorbitol metabolism in nectaries from flowers of Rosaceae. - Funct. Plant Biol. 7: 15, 1980.

Bilger W., Björkman O.: Role of the xanthophyll cycle in photoprotection elucidated by measurements of light-induced absorbance changes, fluorescence and photosynthesis in leaves of Hedera canariensis. - Photosynth. Res. 25: 173$185,1990$.

Chalker-Scott L.: Environmental significance of anthocyanins in plant stress responses. - Photochem. Photobiol. 70: 1-9, 1999.

Dai A.: Drought under global warming: a review. - Wiley Interdiscip. Rev. Clim. Change 2: 45-65, 2011.

Dai A.: Increasing drought under global warming in observations and models. - Nat. Clim. Change 3: 52-58, 2013.

Das P.K., Shin D.H., Choi S.-B., Y.I. Park: Sugar-hormone crosstalk in anthocyanin biosynthesis. - Mol. Cells 34: 501-507, 2012.

Escobar-Gutiérrez A.J., Zipperlin B., Carbonne F. et al.: Photosynthesis, carbon partitioning and metabolite content during drought stress in peach seedlings. - Funct. Plant Biol. 25: 197-205, 1998.

Eveland A.L., Jackson D.P.: Sugars, signalling, and plant development. - J. Exp. Bot. 63: 3367-3377, 2012.

Fang Y., Xiong L.: General mechanisms of drought response and their application in drought resistance improvement in plants. - Cell. Mol. Life Sci. 72: 673-689, 2015.

Flexas J., Diaz-Espejo A.: Interspecific differences in temperature response of mesophyll conductance: food for thought on its origin and regulation. - Plant Cell Environ. 38: 625-628, 2015.

Foyer C.H.: Reactive oxygen species, oxidative signaling and the regulation of photosynthesis. - Environ. Exp. Bot. 154: 134142, 2018.

Genty B., Briantais J.-M., Baker N.R.: The relationship between the quantum yield of photosynthetic electron transport and quenching of chlorophyll fluorescence. - BBA-Gen. Subjects 990: 87-92, 1989 .

Gould K.S.: Nature's swiss army knife: The diverse protective roles of anthocyanins in leaves. - J. Biomed. Biotechnol. 2004: 314-320, 2004.

Gould K.S., Jay-Allemand C., Logan B.A. et al:: When are foliar anthocyanins useful to plants? Re-evaluation of the photoprotection hypothesis using Arabidopsis thaliana mutants that differ in anthocyanin accumulation. - Environ. Exp. Bot. 154: 11-22, 2018.

Govindjee: Chlorophyll $a$ fluorescence: A bit of basics and history. - In: Papageorgiou G.C., Govindjee (ed.): Chlorophyll $a$ Fluorescence: A Signature of Photosynthesis. Advances in Photosynthesis and Respiration. Pp. 1-41. Springer, Dordrecht 2004.

Grimm N.B., Faeth S.H., Golubiewski N.E. et al.: Global change and the ecology of cities. - Science 319: 756-760, 2008.

Harborne J.B.: Spectral methods of characterizing anthocyanins.Biochem. J. 70: 22-28, 1958.

Hatier J.-H.B., Clearwater M.J., Gould K.S.: The functional significance of black-pigmented leaves: Photosynthesis, photoprotection and productivity in Ophiopogon planiscapus 'Nigrescens'. - PLoS ONE 8: e67850, 2013.

Hendrickson L., Furbank R.T., Chow W.S.: A simple alternative approach to assessing the fate of absorbed light energy using chlorophyll fluorescence. - Photosynth. Res. 82: 73-81, 2004.

Hughes N.M., Burkey K.O., Cavender-Bares J., Smith W.K.: Xanthophyll cycle pigment and antioxidant profiles of winterred (anthocyanic) and winter-green (acyanic) angiosperm evergreen species. - J. Exp. Bot. 63: 1895-1905, 2012.

Hughes N.M., Carpenter K.L., Keidel T.S. et al.: Photosynthetic costs and benefits of abaxial versus adaxial anthocyanins in Colocasia esculenta 'Mojito'. - Planta 240: 971-981, 2014. 
Hughes N.M., Morley C.B., Smith W.K.: Coordination of anthocyanin decline and photosynthetic maturation in juvenile leaves of three deciduous tree species. - New Phytol. 175: 675-685, 2007.

Hughes N.M., Neufeld H.S., Burkey K.O.: Functional role of anthocyanins in high-light winter leaves of the evergreen herb Galax urceolata. - New Phytol. 168: 575-587, 2005.

Jiménez S., Dridi J., Gutiérrez D. et al.: Physiological, biochemical and molecular responses in four Prunus rootstocks submitted to drought stress. - Tree Physiol. 33: 1061-1075, 2013.

Karageorgou P., Manetas Y.: The importance of being red when young: anthocyanins and the protection of young leaves of Quercus coccifera from insect herbivory and excess light. Tree Physiol. 26: 613-621, 2006.

Klughammer C., Schreiber U.: Complementary PS II quantum yields calculated from simple fluorescence parameters measured by PAM fluorometry and the Saturation Pulse method. PAM Appl. Notes 1: 27-35, 2008.

Krapp A., Stitt M.: An evaluation of direct and indirect mechanisms for the 'sink-regulation' of photosynthesis in spinach: Changes in gas exchange, carbohydrates, metabolites, enzyme activities and steady-state transcript levels after coldgirdling source leaves. - Planta 195: 313-325, 1995.

Kyparissis A., Grammatikopoulos G., Manetas Y.: Leaf morphological and physiological adjustments to the spectrally selective shade imposed by anthocyanins in Prunus cerasifera. - Tree Physiol. 27: 849-857, 2007.

Landi M., Guidi L., Pardossi A. et al.: Photoprotection by foliar anthocyanins mitigates effects of boron toxicity in sweet basil (Ocimum basilicum). - Planta 240: 941-953, 2014.

Landi M., Pardossi A., Remorini D., Guidi L.: Antioxidant and photosynthetic response of a purple-leaved and a greenleaved cultivar of sweet basil (Ocimum basilicum) to boron excess. - Environ. Exp. Bot. 85: 64-75, 2013.

Landi M., Tattini M., Gould K.S.: Multiple functional roles of anthocyanins in plant-environment interactions. - Environ. Exp. Bot. 119: 4-17, 2015.

Lo Bianco R., Rieger M., Sung S.-J.S.: Effect of drought on sorbitol and sucrose metabolism in sinks and sources of peach. - Physiol. Plantarum 108: 71-78, 2000.

Lo Piccolo E., Landi M., Pellegrini E. et al.: Multiple consequences induced by epidermally-located anthocyanins in young, mature and senescent leaves of Prunus. - Front. Plant Sci. 9: 917, 2018

Manetas Y., Drinia A., Petropoulou Y.: High contents of anthocyanins in young leaves are correlated with low pools of xanthophyll cycle components and low risk of photoinhibition. - Photosynthetica 40: 349-354, 2002.

Manetas Y., Petropoulou Y., Psaras G.K., Drinia A.: Exposed red (anthocyanic) leaves of Quercus coccifera display shade characteristics. - Funct. Plant Biol. 30: 265-270, 2003.

Manzoni S., Vico G., Katul G. et al.: Optimizing stomatal conductance for maximum carbon gain under water stress: a meta-analysis across plant functional types and climates. Funct. Ecol. 25: 456-467, 2011.

McCarthy H.R., Pataki D.E., Jenerette G.D.: Plant water-use efficiency as a metric of urban ecosystem services. - Ecol. Appl. 21: 3115-3127, 2011.

Medrano H., Tomás M., Martorell S. et al.: From leaf to wholeplant water use efficiency (WUE) in complex canopies: Limitations of leaf WUE as a selection target. - Crop J. 3: 220-228, 2015.

Mellisho C.D., Cruz Z.N., Conejero W. et al.: Mechanisms for drought resistance in early maturing cvar Flordastar peach trees. - J. Agr. Sci. 149: 609-616, 2011.

Millennium Ecosystem Assessment: Ecosystems and Human
Well-Being: Synthesis. Pp. 155. Island Press, Washington 2005.

Moustaka J., Panteris E., Adamakis I.-D.S. et al.: High anthocyanin accumulation in poinsettia leaves is accompanied by thylakoid membrane unstacking, acting as a photoprotective mechanism, to prevent ROS formation. - Environ. Exp. Bot. 154: 44-55, 2018.

Napoli M., Massetti L., Brandani G. et al.: Modeling tree shade effect on urban ground surface temperature. - J. Environ. Qual. 45: 146-156, 2016.

Núñez-Florez R., Pérez-Gómez U., Fernández-Méndez F.: Functional diversity criteria for selecting urban trees. - Urban For. Urban Gree. 38: 251-266, 2019.

Pauleit S.: Urban street tree plantings: identifying the key requirements. - Proc. Inst. Civ. Eng.: Munic. Eng. 156: $43-$ 50, 2003.

Pérez-Jiménez M., Hernández-Munuera M., Piñero Zapata M.C. et al.: Two minuses can make a plus: waterlogging and elevated $\mathrm{CO}_{2}$ interactions in sweet cherry (Prunus avium) cultivars. - Physiol. Plantarum 161: 257-272, 2017.

Pinheiro C., Chaves M.M.: Photosynthesis and drought: Can we make metabolic connections from available data? - J. Exp. Bot. 62: 869-882, 2011.

Pinheiro C., Chaves M.M., Ricardo C.P.: Alterations in carbon and nitrogen metabolism induced by water deficit in the stems and leaves of Lupinus albus L. - J. Exp. Bot. 52: 1063-1070, 2001.

Ranney T.G., Bassuk N.L., Whitlow T.H.: Osmotic adjustment and solute constituents in leaves and roots of water-stressed cherry (Prunus) trees. - J. Am. Soc. Hortic. Sci. 116: 684688, 1991.

Rieger M., Lo Bianco R., Okie W.R.: Responses of Prunus ferganensis, Prunus persica and two interspecific hybrids to moderate drought stress. - Tree Physiol. 23: 51-58, 2003.

Ruban A.V.: Nonphotochemical chlorophyll fluorescence quenching: Mechanism and effectiveness in protecting plants from photodamage. - Plant Physiol. 170: 1903-1916, 2016.

Singh S.K., Reddy K.R.: Regulation of photosynthesis, fluorescence, stomatal conductance and water-use efficiency of cowpea (Vigna unguiculata [L.] Walp.) under drought. J. Photoch. Photobio. B 105: 40-50, 2011.

Sjöman H., Hirons A.D., Bassuk N.L.: Improving confidence in tree species selection for challenging urban sites: a role for leaf turgor loss. - Urban Ecosyst. 21: 1171-1188, 2018.

Solfanelli C., Poggi A., Loreti E. et al.: Sucrose-specific induction of the anthocyanin biosynthetic pathway in Arabidopsis. Plant Physiol. 140: 637-646, 2006.

Sotelo P., Pérez E., Najar-Rodriguez A. et al.: Brassica plant responses to mild herbivore stress elicited by two specialist insects from different feeding guilds. - J. Chem. Ecol. 40: 136-149, 2014.

Steyn W.J., Wand S.J.E., Holcroft D.M., Jacobs G.: Anthocyanins in vegetative tissues: a proposed unified function in photoprotection. - New Phytol. 155: 349-361, 2002.

Tattini M., Sebastiani F., Brunetti C. et al.: Dissecting molecular and physiological response mechanisms to high solar radiation in cyanic and acyanic leaves: a case study on red and green basil. - J. Exp. Bot. 68: 2425-2437, 2017.

Turner-Skoff J., Cavender N.: The benefits of trees for livable and sustainable communities. - Plants People Planet 1: 323$335,2019$.

Tyrväinen L., Pauleit S., Seeland K., de Vries S.: Benefits and uses of urban forests and trees. - In: Konijnendijk C., Nilsson K., Randrup T., Schipperijn J. (ed.): Urban Forests and Trees. Pp. 81-114. Springer, Berlin-Heidelberg 2005.

Wang Z., Stutte G.W.: The role of carbohydrates in active osmotic 
adjustment in apple under water stress. - J. Am. Soc. Hortic. Sci. 117: 816-823, 1992.

Winefield C., Davies K., Gould K. (ed.): Anthocyanins: Biosynthesis, Functions, and Applications. Pp. 336. Springer, New York 2009.

Yusof N.L., Rasmusson A.G., Gómez Galindo F.: Reduction of the nitrate content in baby spinach leaves by vacuum impregnation with sucrose. - Food Bioprocess Tech. 9: 13581366, 2016.

Zhang K.-M., Yu H.-J., Shi K. et al.: Photoprotective roles of anthocyanins in Begonia semperflorens. - Plant Sci. 179: 202-208, 2010.

(C) The authors. This is an open access article distributed under the terms of the Creative Commons BY-NC-ND Licence. 